\title{
INTERDISCIPLINARIDADE, ENTRE O CONCEITO E A PRÁTICA Um estudo de caso
}

\section{Susana Cesco \\ Roberto José Moreira \\ Eli de Fátima Napoleão de Lima}

\section{Uma nova área do conhecimento?}

A área interdisciplinar de pós-graduação é, segundo a Coordenação de Aperfeiçoamento de Pessoal de Nível Superior (Capes), a área do conhecimento que mais cresce no Brasil, fruto talvez da necessidade de estabelecer novos diálogos com a sociedade e ajudar a responder aos problemas complexos e híbridos que enfrentamos. Por outro lado, é uma área que contempla diversidade e amplitude quase irrestritas, mesmo dentro dos critérios de avaliação usados pela Capes (2010a) e outras agências de financiamento e avaliação da pós-graduação brasileira, tanto que poderia se pensar que é interdisciplinar o que não se "ajusta” às áreas de formação disciplinares até então autônomas ou o que formou um corpo docente diversificado e que têm pontos de interesse amplos, além de ir das humanidades às ciências naturais e/ou exatas.

Em questôes sociais e tecnocientíficas, a exemplo das atuais discussões em torno de meio ambiente e desenvolvimento, certamente há dimensões políticas, técnicas, culturais e inter-relacionais que só serão percebidas e respondidas quando ultrapassarmos as barreiras disciplinares. Para as dimensões de reconhecimento científico, o desafio da interdisciplinaridade passa, inicialmente, pela questão institucional e estende-se à forma e aos métodos de avaliação dos trabalhos interdisciplinares. Segundo Claude Raynaut, diretor de Pesquisa do Centro Nacional da Pesquisa Científica da França, em entrevista à Assessoria de Comunicação da Capes em 2010,

[...] o recorte disciplinar deu nascimento a territórios de poder, territórios de identificação, que fazem com que seja difícil ultrapassar as 
barreiras e promover a colaboração. Outro desafio é mais intelectual, trata-se de fazer colaborar disciplinas que não vão enxergar os mesmos níveis de realidade. Em particular, fazer colaborar disciplinas que trabalham questóes concretas, práticas e materiais da realidade com outras que trabalham com dimensões não tão palpáveis, imateriais, conceituais (Raynaut, 2010).

No entanto, "fazer colaborar disciplinas que trabalham questões concretas, práticas e materiais da realidade com outras que trabalham com dimensões não tão palpáveis, imateriais, conceituais" não significa, a nosso ver, que não ocorram, nesses casos, a criação e a consolidação de novos "territórios de poder e de identificação" multi ou interdisciplinares, distintos dos disciplinares. Em ambos os casos, a crença ou utopia de uma ciência neutra já não se aplica. O campo da ciência, moderna, clássica ou contemporânea, é também campo de expressão de poderes sociais e culturais, em especial técnico-econômicos. Se reconhecermos essas postulações como aceitáveis, a aceitação do interdisciplinar e do multidisciplinar como campo da ciência é objeto de discussão e disputas, e a própria ideia do que é interdisciplinar ou multidisciplinar precisa ser analisada para se chegar a elucidação das feições da interdisciplinaridade praticada em programas de pós-graduação, especialmente os de ciências sociais. Para tanto, os critérios e diretrizes seguidos para analisar os cursos multi/interdisciplinares pela Capes são importantes e passam pela definição de multidisciplinaridade e interdisciplinaridade, entendidas e avaliadas de formas diversas. Podemos visualizá-los como expressão das forças hegemônicas das ciências brasileiras, expressas em "territórios de poder e identificação" na Capes, no Conselho Nacional de Desenvolvimento Científico e Tecnológico (CNPq), no Ministério de Ciência e Tecnologia e no Ministério de Educação.

Especificamente no âmbito da Capes, cujo sistema de avaliação de pós-graduação foi implantado em 1976, os programas são enquadrados em áreas de concentração. Essas áreas de pertencimento e legitimação são determinadas pelos próprios programas, conforme critérios temáticos e de formação de seu corpo docente, podendo haver solicitação de mudança de área quando as feições do programa mudarem significativamente, caso de muitos programas que migraram nos últimos anos para a área interdisciplinar, criada em 1999 como área multidisciplinar e que, desde 2008, está dividida em grande área multidisciplinar, com uma área interdisciplinar, e suas quatro câmaras temáticas: meio ambiente e agrárias; engenharia/tecnologia/gestão; saúde e biológicas; sociais e humanidades.

No documento da área interdisciplinar que a Capes elabora trienalmente, consta o entendimento dessa agência sobre o assunto como uma área em transição, na qual se constroem referenciais e indicadores, tanto quantitativos quanto qualitativos, objetivando um processo de avaliação mais claro e integrador. Com a separação, em 2008, da grande área multidisciplinar em uma subárea interdisciplinar, os marcos conceituais também passaram por uma reestruturação com base no entendimento que a Capes tem do que seja interdisciplinar e multidisciplinar.

Desde sua criação em 1999, a Coordenação de Área Multidisciplinar, que se tornou Coordenação de Área Interdisciplinar (CAInter) em 2008, é a área que mais cresce na Capes, algo que este órgão percebe como um movimento mundial de crescimento de grupos de pesquisa e cursos que tratam de questóes amplas e complexas:

[...] a importância da introdução de uma área multidisciplinar, em 1999, nomeada a partir de 2008 como interdisciplinar, no contexto da pós-graduação da Capes, decorre da necessidade de se dar conta de novos problemas, de diferentes naturezas e com níveis de complexidade crescentes, que emergem no mundo contemporâneo, muitas vezes decorrentes do próprio avanço dos conhecimentos científicos e tecnológicos, baseados em uma construção do saber notadamente disciplinar (Philippi Jr., 2010, p. 5).

No Brasil, o assunto da interdisciplinaridade nas ciências sociais não é recente. Essa questão foi debatida no III Congresso Nacional de Sociologia, em 1987, que reconheceu a interdisciplinaridade como uma prática emergente incontestável, embora polêmica, nas ciências sociais, mesmo quando se faz referência aos clássicos, segundo Elisa Reis (1987). 
Para reforçar esse posicionamento, a autora cita o compromisso explícito da ciência histórica na obra de Marx, em que "nas versões menos rígidas fica clara a articulação entre análises culturais, econômicas e políticas" (Reis, 1987, p. 3). A ligação inerente entre o sociólogo e o político em Tocqueville e mesmo Durkheim, para quem fatos sociais só poderiam ser explicados por fatos sociais, tem inegavelmente a perspectiva antropológica em seus textos (Idem, pp. 2-3). Além desses autores, Reis aponta e destaca Weber, que desenvolveu um processo de racionalização do qual decorreria a fragmentação inevitável de todas as esferas da vida social. Também nesse sentido J. A. Albuquerque estabelece que "a interdisciplinaridade nas ciências sociais não pode resumir-se a um mero transplante de conceitos, perspectivas ou problemas de uma disciplina em outra" (Albuquerque, 1987, p. 6).

$\mathrm{Na}$ sequência desse debate no campo das humanidades, o livro As assim chamadas ciências sociais, de 1991, é um forte indicativo das inquietações de um grupo de estudiosos de todo o Brasil no que diz respeito ao real sentido das ciências sociais, seus precursores e o caminho traçado desde os anos de 1960 e que são hoje os elementos constituintes de sua face no Brasil. Um dos pontos mais significativos dessa obra é a visão de profissionais distintos sobre o fazer das ciências sociais, e isso se inicia ainda em uma fase de definição e amplitude do campo, e só posteriormente consolidação. Glaucia Villas Bôas conclui desse "período formador” - situado pela autora entre 1945 e 1964 - que

[...] a julgar pelo seu horizonte temático, as ciências sociais nos anos de 1945 a 1964 realmente destacaram os assuntos políticos, abordando-os de diferentes enfoques disciplinares. De modo geral, pode-se dizer que privilegiaram o estudo do Estado brasileiro, através do que questionaram, primeiro, a conquista e a manutenção da unidade territorial e política; segundo, a condução do desenvolvimento econômico do país (Villas Bôas, 1991, p. 29).

Institucionalmente, isso pode ser percebido como um dos reflexos da reforma universitária encetada ainda no final dos anos de 1960 pela Uni- versidade de São Paulo (USP). Renato Ortiz classificou o mesmo processo de institucionalização do conhecimento, identificando características de um "fordismo intelectual", no qual as especialidades, as subdivisões disciplinares e temáticas foram fartamente alimentadas, sem que, no entanto, seus reflexos tenham sido unicamente negativos - é preciso considerar que, de alguma maneira, ele possibilitou a análise mais detalhada de certos eventos (Ortiz, 2004). Posteriormente, esse movimento adquire contornos mais definidos com a nacionalização da pós-graduação, que teve como uma de suas consequências a constituição efetiva de especialidades acadêmicas, a qual deslocou grande parte da produção acadêmica nas ciências sociais dos esforços para entender os processos constitutivos de formação nacional para o problema da modernização (Jackson, 2013). No decorrer dos anos de 1970, em pleno regime militar, o planejamento incorporou-se à ideologia e à prática dos governantes do Brasil. $\mathrm{Na}$ medida em que cresceu a importância do Estado, cresceu também a necessidade de conhecer a realidade sobre a qual ele atuava. $\mathrm{Na}$ mesma época observa-se, segundo Keinert (2011), uma convergência entre iniciativas voltadas ao fomento de instituições acadêmicas de modo geral: "O projeto modernizador posto em prática pelos militares concebia a universidade e o setor de ciência e tecnologia como aspectos cruciais ao desenvolvimento" (Keinert, 2011, p. 3).

Comparativamente a esses temas, as questões culturais, étnicas e raciais receberam muito menos atenção, perfazendo $8,4 \%$ de uma amostra de setecentos livros publicados na área de ciências sociais naquele período e analisados por Glaucia Villas Bôas (1991, p. 29). Pode-se afirmar que em uma disputa de poder "normal" entre áreas disciplinares e seus representantes, as ciências sociais consolidaram-se, no Brasil, ligadas a "pensar o país", com engajamento político, para além do debate acadêmico - este, aliás, muitas vezes influenciado por aquele -, e depois redirecionaram seu foco para o tema do desenvolvimento.

Aqui se faz mister destacar o que e quais são as "ciências sociais", ponto extremamente controverso e muitas vezes dúbio. Como se formou o campo das ciências sociais no Brasil e no mundo? Como 
se desenhou seu currículo? Certamente cada escola entende ciências sociais como um conjunto distinto de áreas. De acordo com a análise de Villas Bôas, na Alemanha a antropologia não faz parte do grupo, na França a história é fundamental para elas e, na Enciclopédia Britânica, a definição de ciências sociais inclui geografia e psicologia social e não história.

Podemos pensar nas definições de interdisciplinaridade, transdisciplinaridade e disciplina inicialmente com base na proposta de Elisa Reis. Ao formular interdisciplinar como "objetivo que designa algo comum a duas ou mais disciplinas ou ramos do conhecimento" e trans como "movimento para além de, através de, posição para além de", ${ }^{1}$ a autora entende que elas integram um universo de conhecimento que as transcende, inscrevendo-as em um movimento para além dos muros austeros da ciência. As ciências sociais fariam parte de "um todo amalgamado que é o Universo da história e da cultura" (Reis, 1991, p. 245).

A importância da multidisciplinaridade recai no fato de não ser um valor em si, mas um valor relacional, que se estabelece em relação às verdades disciplinares. Nesse ínterim, algumas alternativas podem ser exploradas, como a transdisciplinaridade, em que os horizontes disciplinares surgiriam não como um entrave a ser abolido, mas como ponto de partida para uma "viagem" entre saberes compartimentados (Ortiz, 2004).

Ao introduzir o tema da transdisciplinaridade, Nicolescu identifica inicialmente o que considera "o big bang disciplinar”. Para ele, a fragmentação dos saberes responde às necessidades de uma tecnociência sem freios e cuja maior finalidade é a eficácia pela eficácia (Nicolescu, 1999). Ao analisar pluridisciplinaridade e interdisciplinaridade - esta permitindo, em certo grau, a geração de novas disciplinas e a transferência de métodos de uma disciplina para outra - o autor insere a questão da transdisciplinaridade no cenário e a trata como algo que está ao mesmo tempo entre as disciplinas, através das diferentes disciplinas e além de qualquer disciplina. Também assinala que a transdisciplinaridade objetiva conhecer o mundo presente para o qual a unidade do conhecimento é imperativa (Nicolescu, 1999).

Outras análises também sugerem essa necessária ruptura de barreiras ou uma maior liberdade de trânsito para além das fronteiras disciplinares. Frigotto (2008) sugere que a interdisciplinaridade tem duas faces que precisam ser vistas e analisadas separadamente para compreender-se o conjunto. Nesse sentido, é preciso primeiro apreender a interdisciplinaridade como uma necessidade, algo que historicamente se impõe de modo imperativo, e depois como problema, como algo que se apresenta como desafio a ser vencido. Partindo disso, usar a interdisciplinaridade como possibilidade de pesquisa significa desvendar, em um objeto de pesquisa delimitado, as múltiplas determinações e mediações históricas que o constitui.

Delimitar um objeto para a investigação não é fragmentá-lo, ou limitá-lo arbitrariamente. $\mathrm{Ou}$ seja, se o processo de conhecimento nos impõe a delimitação de determinado problema isto não significa que tenhamos que abandonar as múltiplas determinaçóes que o constituem. É neste sentido que mesmo delimitado um fato teima em não perder o tecido da totalidade de que faz parte indissociável (Frigotto, 2008, p. 44).

Ou seja, não podemos simplesmente usar ou adotar categorias analíticas que, ao fim, tornam-se reducionistas, quando o objeto é amplo e subjetivo, ainda mais no campo das ciências sociais. Segundo Frigotto,

[...] o conhecimento do social tem um caráter unitário porque os homens ao produzirem sua existência mediante as diversas relações e práticas sociais o fazem enquanto uma unidade que engendra dimensōes biológicas, psíquicas, intelectuais, culturais, estéticas, etc. Se do ponto de vista da investigação podemos delimitar uma destas dimensões não podemos perder de vista que para que sua compreensão seja adequada é preciso analisá-la na sua necessária relação com as demais dimensôes (Idem, p. 45).

Esse "caráter unitário" apontado pelo autor precisa ser percebido como um conjunto de dimensões e, esse conjunto de dimensões, produz e é produzido pelo outro, como sujeito e em sociedade. Nesse sentido, a interdisciplinaridade pode 
surgir, nas ciências sociais, como ferramenta, mas também como questão/problema. Como problema é mais contundente quando a pesquisa reúne, ou procura reunir, as dimensões particulares de diferentes campos científicos ou de diferentes saberes no que muitas vezes busca atribuir a ideia de uma "totalidade harmônica". Não podemos considerar esse movimento simples, uma vez que conceitos cunhados em uma determinada área e aplicados aos seus objetos específicos de estudo primeiros são apropriados por outra área ou por um trabalho que se define como interdisciplinar, sem que haja uma contextualização e até um redesenho ou ressignificação. Porém, esse universo de conceitos e interpretaçôes que geram termos como multi, pluri, trans ou metadisciplinaridade pode parecer uma tentativa de dividir a interdisciplinaridade para explicá-la, conferir ao termo uma precisão que ele não possui, como bem aponta Nissani (1995), praticando uma interdisciplinaridade já em um texto de 1995.

A interdisciplinaridade não é a simples soma de diversas áreas disciplinares e a mistura de seus conceitos e representaçõos. As práticas interdisciplinares em cada programa de pós-graduação passam por suas objetividades e subjetividades intrínsecas e com suas autonomias relativas, pensando-as, assim, em suas incompletudes e alteridades. As diferenças de cada programa denotam a complexidade e os desafios da interdisciplinaridade e deixam mais claro que a dinâmica dos processos vividos constrói identidades e que estas identidades são abertas e se revelam em seu próprio processo de construção.

Além desse aspecto, permanecem como questôes importantes deste e de outros estudos a localização e o entendimento sobre como a interdisciplinaridade facilitaria ou possibilitaria análises ao mesmo tempo sincrônicas de um tempo histórico e diacrônicas de múltiplos processos sociais expressos nas pesquisas de pós-graduação. Sob esse aspecto, os objetos e/ou áreas de interesse dos diferentes programas de pós-graduação precisam ter seu peso muito bem dimensionado, pois nós dificilmente discutimos a interdisciplinaridade per se. O que fazemos são analises e interpretações acerca de um objeto e, para tanto, buscamos estabelecer a colaboração entre a filosofia, a psicologia, a linguística, a antropologia e outras áreas (Sperber, 2003).

\section{Um estudo de caso}

Apresentamos algumas análises e resultados alcançados em um projeto de pesquisa contemplado pela Capes com uma bolsa Prodoc. Sob o título "A pesquisa interdisciplinar em dissertações e teses do programa CPDA/UFRRJ”, buscamos uma reflexão mais acurada das práticas acadêmicas desse conhecido programa de pós-graduação, especialmente no que diz respeito ao seu foco temático que se apresenta como "desenvolvimento, agricultura e sociedade" e suas práticas interdisciplinares, além da elucidação da epistemologia da interdisciplinaridade - e se haveria uma "epistemologia" no sentido clássico das ciências. Também analisamos a construção do campo das ciências sociais no Brasil e nele a inserção do programa CPDA, com suas características interdisciplinares que ultrapassam a tríade clássica das ciências sociais brasileiras, qual seja, sociologia, antropologia e ciência política.

Inicialmente, observamos a trajetória do CPDA como programa de pós-graduação desde sua criação e posterior vinculação à UFRRJ, considerando os diferentes momentos políticos e sociais de sua institucionalização interdisciplinar. Buscamos com isso incluir o CPDA na história da pós-graduação brasileira e perceber como a proposta de um curso $^{2}$ em "desenvolvimento agrícola" transformou-se em "desenvolvimento, agricultura e sociedade", expandindo, desde 2004, o termo agricultura, para uma significação mais ampla de mundo rural. ${ }^{3} \mathrm{O}$ programa atualmente integra a área de sociologia da Capes, opção que alterou, no início dos anos de 1980, a posição inicial na área de economia. Mesmo inserido na grande área de ciências humanas e na área de sociologia, o CPDA tem uma postura interdisciplinar que ultrapassa o referido tripé clássico das ciências sociais brasileiras e inclui história e economia.

$\mathrm{O}$ enfoque fundamentado em uma abordagem da sociologia do conhecimento científico em busca da elucidação da epistemologia da interdisciplinaridade, ou mesmo se isso existiria, no sentido clássico das ciências, procura identificar condições teórico-metodológicas que instituíram a construção dos objetos de estudo desenvolvidos por professores e alunos do programa CPDA com o objetivo de compreender o campo de possibilidades das práticas 
de pesquisa. Com isso, pretendemos explicitar as orientações gerais de caráter teórico e metodológico que basearam as análises realizadas. Aproximamos o tema da interdisciplinaridade na pós-graduação brasileira e a interpretação da Capes sobre o assunto, por meio de uma compreensão da constituição de paradigmas hegemônicos nas práticas científicas e definindo, assim, a identidade dos programas de pós-graduação como institucionalizações abertas (Moreira e Diaz-Rocha, 2002). Isso se aplica também para a elucidação do campo temático do rural.

Ainda, uma análise da construção do campo das ciências sociais no Brasil parece-nos significativa para o entendimento das escolhas e posturas teórico-metodológicas de muitos programas de pós-graduação - especificamente, do CPDA - cujas práticas interdisciplinares são a espinha dorsal do entendimento do que são e como acontecem suas pesquisas e formulações.

\section{Institucionalizações abertas}

Vista em perspectiva histórica, a pós-graduação no Brasil e, pontualmente, os Programas de pós-graduação, ${ }^{4}$ vivenciaram dinamismos de diversas ordens na sua criação, institucionalização, financiamento e, fundamentalmente, em suas legitimaçōes em comunidades científicas institucionalizadas sob a hegemonia dos enfoques disciplinares da ciência. Estes dinamismos do campo científico envolvem questóes das heranças constituídas e institucionalizadas na formação dos cientistas e de suas subjetividades, das disputas paradigmáticas - teoria e prática -, das políticas de ciência e tecnologia, das legitimações do conhecimento e da verdade científica, mesmo que relativa, que transparece nos conselhos, associações e academias ou nos corpos editoriais de revistas científicas.

Nesse contexto, o conceito de interdisciplinaridade, apoiado em análises sobre a interdisciplinaridade no CPDA e em outros programas, pode ser entendido, conforme Moreira e Diaz-Rocha, ${ }^{5}$ como

[...] o processo de construção de conhecimentos teóricos e de práticas científicas que envolvem a compreensão de realidades complexas que, anteriormente fragmentadas, permitiram análises e sínteses disciplinares. A reconstrução interdisciplinar daquela complexidade envolve assim campos disciplinares em trabalho conjunto, interligados por um objetivo unificado (Moreira e Diaz-Rocha, 2002, p. 11).

Cabe destacar que, desse ponto de vista, uma possível ciência interdisciplinar parece se constituir mais na linha de uma nova ciência ${ }^{6}$ (Capra, 1982) do que numa revolução científica no interior de uma dada ciência (Kuhn, 1989). Partindo da perspectiva de uma diversificada rede de relações, de cooperações e disputas, essa análise permite uma compreensão mais ampla da natureza do entrelaçamento das disciplinas que deram origem a programas interdisciplinares, da formulação de disciplinas (teoria e métodos), linhas de pesquisa e "personalidades" dos atores, além da escolha e identificação dos espaços científicos de institucionalização e legitimação da prática interdisciplinar. Todos esses elementos objetivam-se no momento em que os programas de pós-graduação são avaliados nas comissóes da Capes de acordo com o campo e a área em que estão inseridos. ${ }^{7}$ A diferença de enfoques, percebida quando delimitamos e pontuamos a análise, traz à luz cada uma destas redes de cooperação e disputa e permite, dessa forma, identificar questōes específicas - como seria, em nosso caso, a construção da interdisciplinaridade nos campos das ciências sociais e ciências agrárias.

É importante ter em conta que apesar de institucionalizados e com existências anteriores aos cursos analisados, estas redes sociais pré-existentes (e seus vazios) são dinâmicas, expressam autonomias relativas e estão carregadas de capitais simbólicos, próprios da produção intelectual e científica, tais como títulos, conceitos e reconhecimento científico e suas representações nos comitês científicos da Capes e do $\mathrm{CNPq}$ e nas associações e revistas científicas. Estaremos refletindo sobre estes casos com base na perspectiva de que as identidades sociais dos cursos, dos docentes-orientadores, dos mestres e doutores por eles titulados e da própria interdisciplinaridade - são relacionais. São identidades abertas às tensões dinâmicas de 
seus espaços sociais de inserção (disciplinares e interdisciplinares). (Moreira e Diaz-Rocha, 2002, p. 11).

Partindo desse pressuposto, a construção e/ ou "adaptação" de identidades pelos programas de pós-graduação e os respectivos processos de institucionalização passam por suas objetividades e subjetividades intrínsecas e suas autonomias relativas, assim pensando-as em suas incompletudes e alteridades. As diferenças de cada programa do campo das ciências sociais - estejam eles "inseridos" nas grandes áreas da sociologia, das ciências agrárias ou mesmo na área interdisciplinar - denotam a complexidade e os desafios da interdisciplinaridade, deixam mais claro que a dinâmica dos processos vividos constrói identidades e que estas identidades são abertas e se revelam em seu próprio processo de construção. Cabe destacar a análise dos enfoques disciplinares feita por Moreira:

[...] a relação observador cientista - evento social natural é que constrói a realidade e o próprio objeto cientifico, coloca em cena a cultura científica do observador. Suas teorias e métodos, como componentes construtores dessa realidade científica. A subjetividade-objetividade do observador científico é modulada pela cultura científica moderna e, como demonstra a perspectiva kuhniana, pelo campo disciplinar de sua formação científica. O olhar disciplinar do observador cientista - e a matriz teórico-empírica a ele subjacente - produz determinados fatos científicos [...] (Moreira, 2006, p. 195).

Nesse contexto ganha força a formação das partes para o entendimento amplo do conjunto, ou seja, a formação originária de professores e alunos, aliada as suas preocupações de pesquisa, diz muito sobre os programas de pós-graduação. O CPDA, por exemplo, tem uma mudança clara de perfil desde os anos de 1970, quando foi criado, aos dias atuais. Isso ocorreu em função de uma reorientação em que os temas sociais ganharam destaque nas pesquisas e ultrapassaram o campo da economia, no qual inicialmente se inseria o programa CPDA.
Atualmente, a postulação é de um programa de ciências sociais em que a economia é uma das áreas de interlocução.

Nos anos de 1970, a institucionalização do CPDA como programa de pós-graduação na Fundação Getúlio Vargas era semelhante a um centro de pós-graduação em desenvolvimento agrícola com um curso de mestrado em desenvolvimento agrícola/CMDA, com três áreas de concentração: planejamento agrícola governamental, planejamento agrícola empresarial e desenvolvimento rural integrado. Após o primeiro ano de estabelecimento, o curso foi reestruturado academicamente, em 1978, criando duas áreas de concentração em substituição às três anteriores: estrutura social e organização da produção (Esopa) e estado e política agrícola (EPA) (Lima, 2010, p. 213), na qual os mestres formados eram "destinados" ao serviço público e técnico. Com o passar dos anos - e com o doutorado, a partir de 1995 - o CPDA passou a formar muitos mestres e doutores que se inseriram no mercado como docentes em universidades públicas e privadas. Hoje, a maioria dos egressos do CPDA atua como docentes e não como servidores públicos e/ ou técnicos, o que, claro, não exclui a participação em instituições do setor público agrícola ou do setor público stricto sensu.

$\mathrm{O}$ fato de as agências financiadoras e reguladoras e do próprio Ministério da Educação entenderem a interdisciplinaridade como área forte e agregadora certamente é um estímulo para que novos e diversificados cursos interdisciplinares de graduação e pós-graduação surjam anualmente no Brasil. Também são indicativos da importância crescente da área e da multiplicidade e profundidade dos temas trabalhados atualmente nas ciências sociais.

No caso do CPDA, se o foco inicial do programa era o esforço de modernização tecnológica e de criação de bases empresariais para o setor agrícola, nas décadas de 1980, 1990 e 2000 as questōes sociais ganharam força, e temas relacionados com movimentos sociais, políticas públicas para agricultura e desenvolvimento ou agricultura familiar e grandes propriedades tornaram-se maioria. Nos últimos anos é inegável que o tema do meio ambiente é a questão principal. Um indicador disso são os próprios alunos do CPDA, 
que nos últimos anos buscam temas relacionados às questôes agroambientais, ecológicas ou de sustentabilidade, de forma bastante significativa e digna de registro. Tais alunos buscam no CPDA não apenas um programa de ciências sociais, como normalmente se entendem esses programas no Brasil, mas a possibilidade de um arranjo interdisciplinar que permita a interlocução de suas formações originais com outras áreas e, assim, construírem seus complexos objetos de estudo e pesquisa.

\section{Interdisciplinaridade em desenvolvimento e mundo rural}

Em programas de pós-graduação com forte presença das ciências sociais - independente de ser essa sua área institucional oficial - e cujas temáticas e abordagens articulam-se em torno de questôes de desenvolvimento, sociedade e mundo rural, certamente existe a necessidade de atribuir sentido a essas expressōes. ${ }^{8}$ Segundo Renato Maluf (2000), talvez mais de um sentido, no caso da noção de desenvolvimento, particularmente econômico, especialmente quando aplicado aos processos sociais,

[...] a raiz comum entre desenvolvimento e modernidade evidencia-se nas promessas de rupturas e profundas transformaçôes que ambas as noções carregam, a primeira (desenvolvimento) constituindo-se numa das materializaçôes possíveis da segunda (modernidade), com a ideia de progresso conferindo um sentido positivo a ambas (Maluf, 2000, p. 67).

Nesse sentido, quando pensamos em países ou comunidades e as estratégias de desenvolvimento por eles vivenciadas, identificamos processos de modernização, exceto quando essa transformação está associada a alguma forma de "transformação social por sua vez, associada à hegemonia econômica e a intentos de uniformização cultural que dão origem a contestaçôes em nome da defesa seja da soberania, seja do diverso ou do outro" (Idem, ibidem).

No caso de trabalhos acadêmicos - e especificamente trabalhos de pesquisa realizados no CPDA e que se propuseram a realizar análises sobre o de- senvolvimento -, a palavra desenvolvimento já surge, em muitos casos, associada a uma categoria, quer seja "econômico", "sustentável", "social”, "humano", "nacional", "regional", "rural" ou outra ainda, o que, por vezes, provoca problemas interpretativos e estranhamentos. Essa mesma dificuldade surge quando a temática é o mundo rural. Nessa busca, e diante da necessidade de transcender as fronteiras disciplinares, o maior problema é a dificuldade de encontrar um quadro teórico consistente a partir da interdisciplinaridade. Isso se traduz nas teses e dissertações produzidas nesses programas; muitas delas, aliás, trazem em seus títulos ou dispersos em seus textos a ideia de trabalhar com um dos diversos "tipos" de desenvolvimento ou uma das diversas "definiçôes" de mundo rural. Porém, é importante destacar que o rural discutido e analisado atualmente no CPDA ultrapassa as antigas concepções que o associavam à natureza, à tradição ou que faziam a oposição campo-cidade, em dualidades discursivas geradoras de conceitos e valores considerados superiores e inferiores, como tradicional-moderno, incivilizado-civilizado etc. Esse mundo rural, pensado pari passu à sociedade e ao desenvolvimento, postula a existência de um processo de ressignificação e surge claramente nos trabalhos de professores e alunos. Essa "mudança” de entendimento do que seja o rural é percebida nas teses e dissertações de forma progressiva com o passar do tempo.

No caso específico do CPDA, alguns desses trabalhos foram extremamente bem-sucedidos e conseguiram apresentar aos seus leitores sua interpretação e abordagem, sem deixar de registrar outras correntes interpretativas existentes. Em outros trabalhos, porém, quer seja por opção metodológica ou abordagem, "desenvolvimento" aparece como sinônimo de "crescimento econômico", outras vezes de "progresso" ou ainda "ampliação" e "evolução". Também "mundo rural” aparece apenas como "roça" ou "área agrícola" em outros. O problema, nesses casos, em geral não está na falta de reflexão do autor da tese ou dissertação, ou mesmo em um erro analítico. ${ }^{9}$ A questão é que as ideias ou os conceitos de "desenvolvimento" e "mundo rural" tornaram-se lugares-comuns - dividindo-se o sentido das palavras entre categorias sociais e categorias analíticas - tidos, por vezes, como uma obviedade 
que todos compreendem, prescindindo explicação ou análise. John McNeill denominou isso de "um comando do óbvio": o óbvio em um campo de estudo costuma ser um conhecimento tácito, assim como em um laboratório, e as experiências só podem ser realizadas pessoalmente (McNeill apud Winewater, 2010, p. 19). Para Moreira e Gaviria:

Os valores culturais hegemônicos são de fato aqueles que tendem a nos controlar por dentro, como nossos próprios valores. Esses processos tendem a ser mais poderosos na medida em que cremos que eles foram criados e construídos por nós mesmos, uma espécie de valor particular de nossa própria natureza individual, ou mais ainda valores próprios da natureza humana. Tanto em sua forma individual (natureza do indivíduo), quanto coletiva (natureza da espécie), esses processos podem ser identificados como processos de fetichização, reificação e naturalização dos valores hegemônicos nos quais as identidades individuais se reconhecem, se veem e se identificam com valores, tomando-os como próprios (Moreira e Gaviria, 2002, p. 49).

Porém, é difícil pensar em óbvio em uma sociedade multifacetada ou quando se trabalha com ciências sociais e/ou humanas por trás das noções de desenvolvimento e mundo rural. Além delas, a variável ambiental surge com força nos últimos 25 anos, e o meio ambiente, a natureza ou a sustentabilidade passam a ser percebidos e problematizados em trabalhos que anos antes se referiam, sem problematizar essa variável, à luta por terra, à agricultura familiar, ao agronegócio ou às políticas públicas.

Nosso esforço, a partir dessa explanação, visa atingir a necessidade de compreensão da complexidade que no presente, mais do que no passado, nos impõe como desafios, ou seja, os desafios

[...] dos tempos que tornam cada vez mais imperioso reconhecer que os problemas e suas soluçóes nunca aparecem isoladamente, não podendo, por isso, ser tratados somente de um determinado e exclusivo ponto de vista. Porque fazem parte de uma complexa relação entre ciência, técnica e sociedade, se tratados ou vistos isoladamente, perdem-se a visão de conjunto e o sentido crítico tão necessários ao exercício pleno de uma profissão, por mais técnica que pareça (Costa Flexor e Santos, 2008, p. 7).

\section{Proposta e aplicação}

Pontualmente, e tendo como exemplo de análise programas de pós-graduação interdisciplinares ou de práticas interdisciplinares difundidas, ${ }^{10}$ percebe-se a amplitude dos temas, o extenso leque de formações disciplinares originais que se traduzem em produtividade docente e discente, teses e dissertações, criação de disciplinas, linhas de pesquisa e grupos de estudo.

Quando nos referimos a um programa interdisciplinar, ou com característica interdisciplinar mesmo que vinculado oficialmente à uma área disciplinar, e observamos sua avaliação pela Capes ${ }^{11}$ através de produção acadêmica, adequação do programa aos requisitos da área de avaliação e as teses e dissertaçōes orientadas e defendidas, o vemos em uma perspectiva comparada com outros programas assemelhados. Ou seja, no interior de um mesmo comitê científico, as mesmas variáveis seriam consideradas e os critérios teriam os mesmos pesos, segundo a própria Capes. A divulgação dos dados na internet auxilia a autoavaliação e a reflexão de cada programa, bem como estudos comparados em cada comitê. A observação das "notas/conceitos" atribuídas aos programas e de sua produtividade e possíveis pontos fortes e fracos revela, de alguma forma, os critérios de qualidade validados e legitimados em cada comitê, inclusive os diferentes pesos que cada item tem nos diferentes comitês e sua maior ou menor valorização.

É nesse ponto que consideramos importante a análise de programas de pós-graduação que - mesmo pertencentes a diferentes áreas disciplinares de avaliação ou à área interdisciplinar - têm em comum campos temáticos assemelhados, a fim de: entender os diferentes pesos disciplinares que dão os contornos de cada curso; avançar na elucidação 
das formulações teórico-metodológicas desenvolvidas na análise do mundo rural, como a interdisciplinaridade surge no discurso e nos textos dos discentes; conferir a importância ou não de uma disciplina específica que centralize os debates ou as abordagens; verificar a real dificuldade em se lidar com a colaboração e a cooperação científica, esbarrando em lutas de poder, competição e territorialismos acadêmicos.

Partindo do caso do Programa CPDA/UFRRJ, que se inseriu no comitê de sociologia da Capes no início dos anos de 1980, porém, com características ou práticas interdisciplinares, temos como pontos de destaque primeiro o campo temático - se assim considerarmos "sociedade", "desenvolvimento" e "mundo rural" - e então o corpo docente, diversificado quanto às áreas originais de formação, e a seleção ampla de seus discentes, cujas áreas originais de formação são diversas e não restritivas.

De acordo com Capra (1982, p. 259), a nova visão de realidade associada a uma concepção sistêmica da vida baseia-se na consciência do estado de inter-relação e interdependência essencial de todos os fenômenos físicos, biológicos, psicológicos, sociais e culturais. Essa visão requer que se transcendam as fronteiras disciplinares e conceituais.

Nestes sentidos estão em disputa visões distintas sobre a realidade de cada campo disciplinar e do próprio campo científico. $\mathrm{Na}$ medida em que a ciência fala sobre a realidade social e sobre a socialização da natureza, também estão em disputa visōes distintas de sociedade. Neste contexto os próprios conceitos e significados de desenvolvimento, de rural e de sustentabilidade são criticados e estão sujeitos a processos de ressignificação, dependendo da dinâmica do embate e dos conteúdos postos em disputa (Moreira, 1996, p. 67).

Isso passa pelo entendimento e consequente prática da interdisciplinaridade na formulação de grades curriculares, programas de cursos e na formação geral de mestrandos e doutorandos, cujos trabalhos finais (teses e dissertações) refletem seu percurso formativo dentro dos programas de pós-graduação por eles escolhidos. A própria inserção desses programas em departamentos e institutos no universo maior da estrutura universitária e de comissões e conselhos normativos, formativos e avaliativos, como a Capes e o $\mathrm{CNPq}$, indica, além da referida diversidade do corpo docente e discente, os critérios de seleção e a grade disciplinar.

É igualmente importante destacar que essa multiplicidade serve para ampliar a prática interdisciplinar acionando a diversidade disciplinar e a consequente incorporação de áreas analíticas amplas. Soma-se também ao conceito da Capes de interdisciplinaridade ${ }^{12}$ - e cria nova tensão - a noção de Leff sobre o tema, pela qual a interdisciplinaridade, vista como integração, "não se dá pela via de uma completude de algo que falta às ciências e que é preenchido com os conteúdos de outras ciências e de outros saberes, mas como esse algo que as impulsiona a reconstituir-se desde outro lugar, desde outra racionalidade" (Leff, 2004, p. 35). Essa é mais uma leitura que dimensiona a complexidade inerente aos cursos e programas de pós-graduação que assim se definem ou praticam a interdisciplinaridade. É válida a reflexão sobre esses casos com base na perspectiva de que as identidades sociais percebidas nos cursos e em seus professores e alunos são relacionais, são identidades abertas às tensões dinâmicas de seus espaços sociais de inserção, sejam eles disciplinares e/ou interdisciplinares (Moreira e Diaz-Rocha, 2002).

Um dos objetivos iniciais do programa CPDA era gerar conhecimentos sobre a agricultura brasileira e formar quadros para o Sistema Nacional de Planejamento Agrícola (SNPA), ou seja, formar gestores e pesquisadores para a administração pública do desenvolvimento agrícola nacional, com perspectiva de expansão dessas atividades para América Latina e Caribe, tudo isso sob a ideia de desenvolvimento agrícola no decorrer da década de 1970. Nesse sentido, o campo "desenvolvimento agrícola" tem uma matriz centrada nas teorias de desenvolvimento com suas interfaces com a economia (ideia de desenvolvimento econômico), com a economia rural e com a sociologia rural. Todo esse processo de criação e consolidação impôs, como seria de se esperar, alguns campos de disputa e de cooperação que foram fundamentais na definição dos atuais contornos do programa de 
pós-graduação em ciências sociais em desenvolvimento, agricultura e sociedade da UFRRJ. Estabeleceu inclusive os perfis dos novos docentes incorporados ao programa nos últimos anos, que forçam uma nova leitura sobre o que o CPDA, como programa, entende por interdisciplinaridade e quais os novos pontos fortes dessa interdisciplinaridade ou se os antigos referenciais mantêm-se fortes. Pontualmente, a interdisciplinaridade está posta no CPDA nos conteúdos das disciplinas, objetivando a visualização de dimensões diferenciadas de objeto-problema acessível por diferentes abordagens.

É interessante registrar que, já na postulação de criação do curso de mestrado em desenvolvimento agrícola (CMDA), estava inscrita a preocupação com a realização de um curso "que permitisse, além de suas atividades docentes no âmbito da pós-graduação, a elaboração de pesquisas voltadas para a problemática do mundo rural brasileiro" (Vale, 1979). ${ }^{13}$

O princípio que norteou a estruturação do CMDA foi o de que o estágio em que se encontrava o processo de consolidação do Sistema Nacional de Planejamento Agrícola exigia não apenas a formação de pessoal para operá-lo, mas, igualmente, a formação de quadros capacitados a implantar e gerir o sistema em pauta, demandando dessa forma, técnicos que possuíssem sólidos conhecimentos de natureza conceitual e instrumental.

O curso, assim, seria "parte integrante do esforço global de modernização tecnológica e de bases empresariais para o setor agrícola, que deveria apoiar-se em um conjunto de projetos integrados a serem executados pelas universidades" (idem, ibidem, grifos nossos), instituições de ensino e pesquisa, associações e órgãos de classe, sistemas de assistência e extensão rural, e outros, concebidos em função dos diversos níveis da clientela, de modo a influir efetivamente no comportamento do empresário e da empresa rural. A orientação geral de sua criação propunha formar recursos humanos habilitados a implantar e gerir os órgãos públicos e os demais organismos vinculados ao SNPA, concomitantemente capacitados a pesquisar a realidade do setor, propositivos em apontar soluçóes para os problemas que afetavam o setor e, através da atividade docente, contribuir para a formação da massa crítica, requerida para a modernização do setor. Portanto, o objetivo maior do curso seria o de usar seus egressos como elementos de disseminação de novas práticas gerenciais, promovendo-se, por esse meio, um efeito multiplicador de treinamento e, mais do que isso, podemos dizer, como intelectuais orgânicos do mundo agrário modernizado.

Quanto à preocupação devida à dicotomia entre formação conceitual e instrumental, chegou-se ao consenso de que o curso constituir-se-ia como tentativa de recompor o equilíbrio entre os dois tipos complementares de formação. Relativamente à contradição entre formulação e implementação de planejamento de desenvolvimento, partia-se do pressuposto que, até alguns anos passados, a ênfase em matéria de planejamento havia se concentrado mais na área de formulação do que na de implementação de planos e programas, na medida em que se fazia necessário vencer uma série de obstáculos que se opunham à estruturação de órgáos de planejamento e aos próprios valores implícitos no conceito de plano, dadas as vicissitudes da condição de país em desenvolvimento. Desse modo, o desafio residia, primordialmente, em elevar o nível de efetividade dos sistemas nacionais de planejamento por meio da criação de mecanismos institucionais adequados e, sobretudo, da formação de recursos humanos capacitados a gerir tais sistemas.

Nessas condiçôes, o CMDA deveria atuar como matriz de instrutores para a execução do ambicioso e extremamente importante programa de formação de recursos humanos do Ministério da Agricultura, na segunda metade da década de 1970 . Os antecedentes do CPDA estão diretamente vinculados ao esforço que se realizava, em escala mundial, para a estruturação e operacionalização de sistemas de planejamento agrícola, tanto em países desenvolvidos quanto naqueles em vias de desenvolvimento. ${ }^{14}$

Especialmente no início, o CPDA postulava, em sua primeira reforma, em 1978, uma problematização a partir da administração pública, através de análises multidisciplinares que necessariamente extrapolavam os campos da economia e da economia e sociologia rurais, como formaçóes disciplinares autônomas. Esse diálogo com as ciências sociais, a ênfase nas questôes agrárias e nas políticas para o campo nos faz pensar no CPDA como uma política pública de atuação no governo, via 
Ministério da Agricultura, com a finalidade de formação e direcionamento dos profissionais que trabalhariam na administração pública voltada àquele "novo" rural gestado e autoritariamente configurado no então governo militar.

É preciso reconhecer aqui a existência de um grande desequilíbrio entre o curso de mestrado e o programa de história da agricultura brasileira, de importância e reconhecimento significativos quando o objetivo era o de subsidiar SNPA. Tratava-se de um curso de economia tradicional, permeado por questôes de ciências sociais que "abriam brechas nas certezas tecnicistas, mas que eram [ainda] marginais" (Delgado, 2010, p. 155). Assim, de acordo com o mesmo autor, era um problema central favorecer o crescimento do curso com coerência e legitimidade e contornar as pressões do Ministério da Agricultura e da Fundação Getúlio Vargas, que precisavam ser enfrentadas democraticamente. Era necessário "gerir essas pressões de forma que o curso avançasse e não perdesse as características centrais de ser um programa, ao mesmo tempo crítico e que buscava caminhos inovadores e multidisciplinares para a análise da questão agrícola" (Idem, ibidem).

A trajetória do CPDA teve alterações estruturais e teórico-metodológicas na busca por uma identidade própria. Nesse processo de autoafirmação, questôes como financiamentos e quem seriam os professores e os alunos do programa tiveram peso fundamental, além da vinculação institucional e dos novos rumos políticos do início dos anos de 1980. Para Moreira e Diaz-Rocha, o programa tinha características muito mais de cooperação multidisciplinar do que do diálogo interdisciplinar das ciências sociais. Esse diálogo se construiria como subproduto da busca de uma compreensão mais ampla do mundo rural do período.

Desde fins dos anos [19]70 e o início dos [19]80, a sociedade brasileira vivenciava um contexto de contestação à ordem econômica política e social consolidada a partir de 1964 . A crítica ao "milagre brasileiro" e à ordem política conformam a reorganização da sociedade civil e luta pela redemocratização que se expressam no processo constituinte e na Cons- tituição de 1988. Em sintonia com estes processos, o CPDA aprofundou a análise crítica das relações entre agricultura e sociedade num contexto de reorganização da sociedade civil, da redemocratização e de suas expressões no campo (Moreira e Diaz-Rocha, 2002, p. 10).

Das primeiras dissertações, defendidas no fim dos anos de 1970, à primeira década dos anos 2000, as mudanças são percebidas desde as abordagens até o foco teórico-metodológico. No princípio, os trabalhos versavam sobre planejamento da agricultura, formas sociais de organização da produção, comercialização, trabalho e sindicatos ligados ao campo, além da perspectiva de análise histórica da agricultura e urbanização dos espaços rurais. Não necessariamente os objetos mudaram em sua totalidade, mas, além dos novos objetos incorporados ao leque de pesquisas desenvolvidas, surgiram novas abordagens, especialmente voltadas ao estudo da modernização do campo e das novas tecnologias e, em contraponto, da pequena produção familiar e movimentos sociais; recentemente, trata-se de segurança alimentar, instituições, mercados e regulação, história agroambiental, estudos de consumo, entre outros temas. Percebe-se nesse percurso institucional, inclusive de mudança de nome, que o programa CPDA manteve parte de sua nomenclatura original ressignificando e ampliando sua atuação.

Esse movimento pode ser inserido no que um editorial da revista Estudos Avançados definiu como "valores de uma época e sua tradução em palavras", especialmente no caso do termo "desenvolvimento", mas que também é pertinente para a noção de mundo rural ou agrícola.

Há palavras que definem os valores de uma época. Civilização, progresso, evolução foram os termos-chave do século XIX. Ao longo do século XX, preferiu-se desenvolvimento, termo que ainda serve de motor e guia ao pensamento que informa os projetos das naçôes contemporâneas. Mas, no bojo desse mesmo conceito central, vêm se formando valores igualmente, básicos, e que têm a ver com certos aspectos críticos do desenvolvimento econômico (Estudos Avançados, 2012, p. 2). 
$\mathrm{Na}$ contemporaneidade, a sociedade organizada exige, cada vez mais, que o crescimento econômico não ignore as normas democráticas, especialmente as que direcionam a relação entre o ser humano e a sua morada, a natureza. "A palavra-chave para conceituar essa dimensão é sustentabilidade; quando acoplada à matriz econômica, serve para dar-lhe uma conotação ética: o valor resultante é o desenvolvimento sustentável" (Idem, p. 2). Essa é, atualmente, uma variável nova e imprescindível nas discussóes interdisciplinares, tanto do CPDA como de outros programas de pós-graduação cujo foco temático esteja ligado ao mundo rural, ao desenvolvimento e à sociedade.

\section{Notas}

1 Segundo a autora, essas são as definições contidas em um dicionário de língua portuguesa - não especificado por ela -, consultado quando da redação do texto.

2 O Centro de Pós-Graduação em Desenvolvimento Agrícola da Escola Interamericana de Administração Pública (Eiap) da Fundação Getúlio Vargas (FGV) foi instalado em 1976 através de convênio entre o Ministério da Agricultura/Suplan e o Instituto Brasileiro de Desenvolvimento Florestal (IBDF). O curso de mestrado em desenvolvimento agrícola foi criado em 1977.

3 Na contemporaneidade - em um contexto de mudanças no qual o rural não mais se confunde com o agrícola e as questôes relativas à agricultura expandiram seu significado - o programa tem atuação interdisciplinar de ensino, pesquisa, extensão e intercâmbio de ciências sociais aplicadas ao conhecimento do mundo rural e áreas afins.

4 Nosso olhar recai, especialmente, sobre os programas cujo campo temático aproxima-se do estudo de caso primeiro que deu origem a esse trabalho - desenvolvimento, agricultura e sociedade - e das práticas interdisciplinares na pós-graduação.

5 Moreira e Diaz-Rocha (2002) aplicam essa análise comparativa para programas de ciências ambientais como: ecologia, conservação e manejo de vida silvestre (ECMVS), da Universidade Federal de Minas Gerais; meio ambiente e desenvolvimento (MAD), da Universidade Federal do Paraná; psicossociologia de comunidade e ecologia social (Eicos), da Universidade Federal do Rio de Janeiro; ciência ambiental (Procam), da Universidade de São Paulo.
6 Para Capra (1982), as transformações que vivenciamos colocam em questão o próprio paradigma científico herdado e apontam para rupturas das perspectivas dualistas e disciplinares e até dos pressupostos filosóficos básicos da ciência herdada do cartesianismo.

7 A classificação original das áreas do conhecimento abrangia oito grandes áreas, 76 áreas e 340 subáreas. Em 2008, a Capes criou a grande área multidisciplinar e, dentro dela, a área interdisciplinar com quatro subáreas: meio ambiente e agrárias; engenharia/tecnologia/gestão; saúde e biológicas; e sociais e humanidades.

8 A base analítica que deu origem a este estudo tomou como referência os programas de pós-graduação em extensão rural da Universidade Federal de Viçosa, o programa de pós-graduação em desenvolvimento rural da Universidade Federal do Rio Grande do Sul e o programa de pós-graduação em desenvolvimento sustentável da Universidade de Brasília.

9 Essa análise tem por base um estudo amplo das teses e dissertações defendidas no CPDA, especialmente depois de sua reestruturação no ano de 2004. Esse trabalho está sendo finalizado dentro das pesquisas de um projeto Prodoc da Capes e buscou também uma análise comparativa com o período anterior, já estudado em outros projetos dos autores. Para fins desse artigo optamos por não citar ou analisar pontualmente trabalhos, quer de estudantes ou de professores do programa, com o objetivo de buscar identificar as "feições institucionais" mais amplas, moldadas a partir de seus "resultados" e/ou "produtos" (livros, artigos, teses e dissertações).

10 Nossa proposta é fazer uma análise de programas distintos, inseridos em áreas distintas de avaliação e que geram articulações distintas. Porém, seus temas de pesquisa, que giram em torno do "desenvolvimento", "mundo rural" e "sociedade", além da interdisciplinaridade, são elementos agregadores e justificam a escolha dos programas de pós-graduação citados anteriormente como nossos objetos de estudo.

11 Quando nos referimos às avaliações de áreas da Capes estamos sempre citando os documentos de área das áreas interdisciplinar, sociologia e ciências agrárias, disponíveis no site da Capes, em especial as avaliações dos programas de pós-graduação aqui analisados.

12 O conceito da Capes de interdisciplinaridade, que consta em seu documento de área, é a convergência de duas ou mais áreas do conhecimento, em que métodos de uma são transferidos para a outra, gerando novos saberes e uma nova metodologia. 
13 Raul Octávio Amaral do Vale, à época secretário nacional de Planejamento Agrícola.

14 A narrativa dessas informaçôes inspirou-se em documentos de circulação interna da época de sua proposição, em 1977, de acordo com Lima (2010).

\section{BIBLIOGRAFIA}

ALBUQUERQUE, J. A. G. (1987), “A interdisciplinaridade é possível?”. Anais do III Congresso Nacional de Sociologia. Brasília.

BOMENY, Helena \& BIRMAN, Patrícia (orgs.). (1991), As assim chamadas ciências sociais: formação do cientista social no Brasil. Rio de Janeiro, Uerj/Relume Dumará.

BASSO, David. (2004), Estratégias agroindustriais e desenvolvimento sustentável. Tese de doutorado. Rio de Janeiro, CPDA/UFRJ.

CAPES. (2010A), "Documento de área: sociologia”. Disponível em <http://conteudoweb.capes.gov.br/conteudoweb/ $\mathrm{Vis}$ ulizadorServlet? no me $=/ 2010 /$ doc_area/2010_034_Doc_Area.pdf\&aplicaca $\mathrm{o}=$ avaliacaotrienalProjetoRelacaoCurso\&idEta $\mathrm{pa}=$ undefined $\&$ ano $=$ undefined $\&$ tipo $=$ undefin ed>. Acesso em 24 jun. 2013.

. (2010B), "Documento de área: ciências agrárias”. Disponível em <http:// conteudoweb.capes.gov.br/conteudoweb/ VisualizadorServlet? nome $=/ 2010 / \mathrm{doc}_{-}$ area/2010_042_Doc_Area.pdf\&aplicacao=ava liacaotrienalProjetoRelacaoCurso\&idEtapa $=\mathrm{u}$ ndefined $\&$ ano $=$ undefined $\&$ tipo $=$ undefined $>$. Acesso em 24 jun. 2013.

CAPES. (2010C), "Documento de área: interdisciplinar”. Disponível em <http:// conteudoweb.capes.gov.br/conteudoweb/ VisualizadorServlet? nome $=/ 2010 / \mathrm{doc}_{-}$ area/2010_045_Doc_Area.pdf\&aplicacao=ava liacaotrienalProjetoRelacaoCurso\&idEtapa $=\mathrm{u}$ ndefined $\&$ ano $=$ undefined $\&$ tipo $=$ undefined $>$. Acesso em 24 jun. 2013.

CAPRA, Fritjof. (1982), O ponto de mutação: a ciência, a sociedade e a cultura emergente. São Paulo, Cultrix.

CHARTIER, Roger. (2003), Formas e sentido, cultura escrita: entre distinçāo e apropriação. Campinas, SP, Mercado das Letras.

COSTA, Luiz Flávio C.; FLEXOR, Georges \& SANTOS, Raimundo (orgs.). (2008), Mundo rural brasileiro: ensaios interdisciplinares. Rio de Janeiro, Edur/Mauad/Seropédica.

DELGADO, Nelson G. (2009), "Política econômica, ajuste externo e agricultura”, in Sérgio Leite (org.), Políticas públicas e agricultura no Brasil, 2. ed., Porto Alegre, Editora da UFRGS.

DELGADO, Nelson G. (2010), "Depoimentos", in Eli Napoleão de Lima e Sérgio Pereira Leite (orgs.), CPDA 30 Anos: desenvolvimento, agricultura e sociedade, Rio de Janeiro, Edur/ Mauad/Seropédica.

ESTUDOS AVANÇADOS. (2012), "Editorial”. Estudos Avançados, 26 (74): 2. Disponível em <http://dx.doi.org/10.1590/S010340142012000100001>.

FRIGOTTO, Gaudêncio. (2008), "Interdisciplinaridade como necessidade e como problema nas ciências sociais". Ideação: Revista do Centro de Educação e Letras da Unioeste, 10 (1): 41-62.

KEINERT, Fábio Cardoso. (2011), "Cientistas sociais entre ciência e política (Brasil, 19681985)”. Anais do XXVI Simpósio Nacional de História Anpuh. São Paulo.

KOSELLECK, Reinhart. (2006), Futuro passado: contribuição à semântica dos tempos históricos. Rio de Janeiro, Contraponto Editora/Editora PUC-Rio.

KUHN, Thomas. (1989), A estrutura das revoluçôes cientificas. São Paulo, Perspectiva.

LIMA, Eli Napoleão de \& LEITE, Sérgio Pereira. (2010), CPDA 30 Anos: desenvolvimento, agricultura e sociedade. Rio de Janeiro, Edur/ Mauad/Seropédica.

LINHARES, Maria Yedda Leite. (1979), História do abastecimento: uma problemática em questão (1530-1918). Brasília, Binagri.

MALUF, Renato S. (2000), "Atribuindo sentido(s) à noção de desenvolvimento econômico". Estudos Sociedade e Agricultura, 15: 53-86.

MOREIRA, Roberto José. (1996), "Disputas paradigmáticas nos programas de pós-graduação em economia e desenvolvimento rural". Estudos Sociedade e Agricultura, 6: 65-80. 
(2006), "Identidades complexas no conhecimento científico sobre comunidades costeiras", in Nora Beatriz Presno Amodeo e Héctor Alimonda (orgs.), Ruralidades, capacitação e desenvolvimento, Belo Horizonte, UFV/CPDA.

MOREIRA, Roberto José \& DIAZ-ROCHA, Paulo Ernesto. (2002), "Interdisciplinaridade na pós-graduação: notas de pesquisas". Redes, 7 (2): 9-45.

MOREIRA, Roberto José \& GAVIRIA, Margarita Rosa. (2002), "Territorialidades, ruralidades e assimetrias de poder na Comunidade de Taquari”. Estudos Sociedade e Agricultura, 18: 47-72.

MOURA, Alexandrina Sobreira de. (1987), "Interdisciplinaridade nas ciências sociais". Anais do III Congresso Nacional de Sociologia. Brasília.

NICOLESCU, Basarab. (1999), O manifesto da transdisciplinaridade. São Paulo, Triom.

NISSANI, Moti. (1995), "Fruits, salads, and smoothies: a working definition of interdisciplinarity". Journal of Educational Thought, 26 (2). Disponível em <http://www.is.wayne.edu/ mnissani/pagepub/smoothie.htm $>$. Acesso em 12 maio 2012.

ORTIZ, Renato. (2004), "Estudos culturais". Tempo Social, 16 (1). Disponível em $<$ http://www.scielo.br/scielo.php?script=sci arttext\&pid=S0103-20702004000100007\&ln $\mathrm{g}=\mathrm{en} \& \mathrm{nrm}=\mathrm{iso}>$. Acesso em 18 jun. 2013.

(ORG.). (2003), A sociologia de Pierre Bourdieu. São Paulo, Olho d"Água.

PHILIPPI JR., Arlindo. (2010), Relatório de avaliação 2007-2009: trienal 2010. Disponível em <http://trienal.capes.gov.br/ wp-content/uploads/2011/01/INTERDISCIPLINAR-RELAT\%C3\%93RIO-DE-AVALIA\%C3\%87\%C3\%83O-FINAL.pdf>. Acesso em 20 abr. 2011.

REIS, Elisa P. (1987), "Sociologia e Ciências Sociais no Brasil: a questão da interdisciplinaridade". Anais do III Congresso Nacional de Sociologia. Brasília.

RAYNAUT, Claude. (2010), Entrevista à assessoria de comunicação da Capes, 30 nov. Disponível em <http://www.capes.gov.br>. Acesso em 28 fev. 2011.
SEN, Amartya Kumar. (2000), Desenvolvimento como liberdade. São Paulo, Companhia das Letras.

SPERBER, Dan. (2003), "Why rethink interdisciplinarity?". Virtual Seminar Rethinking Interdisciplinarity. Paris, CNRS/Institut Nicod. Disponível em <http://www.interdisciplines. org/medias/confs/archives/archive_3.pdf > . Acesso em 15 jun. 2012.

VALE, Raul Octávio Amaral do, (1979), "Apresentação", in Maria Yedda Leite Linhares, História do abastecimento: uma problemática em questão (1530-1918). Brasília, Binagri.

VIANNA, Luiz Werneck et al. (1998), "Doutores e teses em ciências sociais". Dados, 41 (3). Disponível em <http://www.scielo.br/ scielo.php?script=sci_arttext\&pid=S0011$-52581998000300001 \& \operatorname{lng}=\mathrm{en} \& \mathrm{nrm}=\mathrm{iso}>$. Acesso em 10 jun. 2013.

VILLAS BÔAS, Glaucia. (1991), "A tradição renovada", in Helena Bomeny e Patricia Birman (orgs.), As assim chamadas ciências sociais: formação do cientista social no Brasil, Rio de Janeiro, Uerj/Relume Dumará,

WINEWARTER, Verena. (2010), "Abordagens sobre a História Ambiental: um guia de campo para os seus conceitos". Abordagens Geográficas, 1 (1): 1-21. 


\section{INTERDISCIPLINARIDADE, ENTRE O CONCEITO E A PRÁTICA: UM ESTUDO DE CASO}

\section{Susana Cesco,}

Roberto José Moreira e

Eli de Fátima Napoleão de Lima

Palavras-chave: Interdisciplinaridade; Pós-Graduação; Desenvolvimento; Mundo rural; Ciências sociais.

Interdisciplinaridade é, hoje, tema relevante na constituição de cursos e na construção de conhecimento nas instituiçôes de ensino superior, especialmente na pós-graduação, não apenas no Brasil. Nesse sentido, a análise da construção do campo das ciências sociais no Brasil é significativa para o entendimento das escolhas e posturas teórico-metodológicas de muitos programas de pós-graduação cujas práticas interdisciplinares são a "espinha dorsal" do entendimento do que sejam e como acontecem suas pesquisas e formulaçôes. Inicialmente, foi analisada a trajetória do Programa CPDA/UFRRJ, considerando os diferentes momentos políticos e sociais de sua institucionalização interdisciplinar. Combinando consulta a documentos institucionais, fontes secundárias, observações e entrevistas, o artigo examina a interdisciplinaridade na pós-graduação, sua construção e institucionalização e seus resultados desejados e/ou imprevistos.

\section{INTERDISCIPLINARITY, BETWEEN THE CONCEPT AND THE PRACTICE: A CASE STUDY}

\author{
Susana Cesco, \\ Roberto José Moreira and \\ Eli de Fátima Napoleão de Lima
}

Keywords: Interdisciplinarity; Graduate studies; Development; Rural world; Social sciences.

Interdisciplinarity is now a relevant issue in the organization of courses and the construction of knowledge in higher education institutions, especially in graduate studies. The analysis of the construction of the field of Social Sciences in Brazil is significant for understanding the choices and the theoretical-methodological approaches of many graduate programs whose interdisciplinary practices are the "backbone" of their researches and formulations. This article analyzes initially the trajectory of the CPDA Program of the UFRRJ, considering the different political and social moments of its interdisciplinary institutionalization. Combining the consultation of institutional documents, secondary sources, observation and interviews, the article examines interdisciplinarity in graduate studies, its construction and institutionalization, and its aimed and/or unforeseen outcomes.

\section{INTERDISCIPLINARITÉ, ENTRE LE CONCEPT ET LA PRATIQUE: UNE ÉTUDE DE CAS}

\author{
Susana Cesco, \\ Roberto José Moreira et \\ Eli de Fátima Napoleão de Lima
}

Mots-clés: Interdisciplinarité; Études de $3^{\text {ème }}$ cycle; Développement; Monde rural; Sciences sociales.

L'interdisciplinarité constitue, de nos jours, un thème important dans la création de cours et la construction du savoir dans les institutions d'enseignement supérieur, particulièrement dans les études de $3^{\text {ème }}$ cycle, aussi bien au Brésil qu'ailleurs. Ainsi, lranalyse de la construction du domaine des sciences sociales au Brésil est significative pour la compréhension des choix et des positions théoriques et méthodologiques de plusieurs programmes de $3^{\text {èm }}$ cycle dont les pratiques interdisciplinaires constituent "leépine dorsale" de la compréhension de ce que sont leurs recherches et leurs formulations et de quelle façon elles ont lieu. Nous avons initialement analysé la trajectoire du Programme CPDA/ UFRRJ, tout en considérant les différents moments politiques et sociaux de son institutionnalisation interdisciplinaire. Tout en associant la consultation de documents institutionnels à des sources secondaires, des observations et des entretiens, lyarticle examine linterdisciplinarité dans les cours de choix et des positions théoriques et méthodologiques de plusieurs programmes de $3^{\text {ème }}$ cycle, leur construction et leurs institutionnalisation ainsi que les résultats souhaités et /ou imprévus. 